\title{
Income levels and mortality rates in patients with chronic kidney disease in South Korea: a population- based cohort study using national health insurance data
}

\author{
Young Choi * \\ Department of Health Care Management, Catholic University of Pusan, 57, Oryundae-ro, Geumjeong-gu, \\ Busan 46252, Korea \\ * Corresponding author: choiyoung223@gmail.com; Tel: 82-51-510-0553; Fax: 82-51-510-0618
}

\begin{abstract}
Background: To examine the association between income levels and mortality rates in patients with chronic kidney disease. Methods: We analyzed data obtained from 3,172 patients with chronic kidney disease obtained from the Korean National Health Insurance claims database (2003-2009). Each patient was monitored until December 2010 or until death, whichever came first. Individual income was estimated from the national health insurance premium. Information on mortality was obtained from the Korean National Statistical Office. Cox proportional hazard models were used to compare mortality rates between different income groups after adjusting for possible confounding risk factors. Results: A low income was significantly associated with a high mortality rate after adjusting for covariates (adjusted HR 1.298 [1.082-1.556]). In addition, dialysis patients who had low incomes were more likely to have higher mortality rates compared to those in dialysis patients who had high incomes (adjusted HR 1.528 [1.122-2.082]). Conclusion: The findings of this study indicate that chronic kidney disease patients with low incomes have the highest mortality risk. Promotion of targeted policies and priority health services for patients with low incomes may help reduce the mortality rate in this vulnerable group.
\end{abstract}

Keywords: chronic kidney disease; low socioeconomic status; mortality

\section{Introduction}

Chronic kidney disease (CKD) is considered to be one of the major public health challenges [1, $2]$, as it is a severe condition that reduces life expectancy and typically progresses to end-stage renal disease (ESRD), requiring renal replacement therapy. The progressive nature of $C K D$, the ensuing ESRD, and associated cardiovascular morbidity and mortality are putting a considerable burden on global health care resources [1]. Recent findings from the Global Burden Disease (GBD) 2010 study have highlighted CKD as an important cause for global mortality across the world including Asian countries [3, 4]. Moreover, disadvantaged populations across the globe exhibit a disproportionate burden of CKD because of differences in CKD occurrence and outcomes [5]. Although many CKD risk factors can be managed and modified to optimize clinical outcomes, the prevailing socioeconomic and cultural factors in disadvantaged populations militate against optimum clinical outcomes [5]. In addition, disadvantaged populations exhibit a broader spectrum of CKD risk factors and may be genetically predisposed to an earlier onset and a more rapid progression of chronic kidney disease [5].

Socioeconomic disparities in health are well recognized in a wide range of disease [6]. CKD is of particular interest in the study of health inequalities as, like many chronic diseases, there is a marked social gradient in health outcomes. Individuals of low socioeconomic status (SES) have a higher risk for incidence compared to that in those of high SES [7, 8]. Social disadvantages, including low SES [9, 10], neighborhood deprivation [11], and minority ethnicity [12] were found to be strongly associated with high rates of CKD. Moreover, individuals of low SES have limited 
access to health care resources [13-15], lower glomerular filtration rate [16], higher progression of CKD [17-19], higher incidence of cardiovascular events [20], higher mortality rates [21-26], and poorer quality of life [27] compared to those in individuals of high SES. There is also consistent evidence that individuals of low SES with CKD have limited access to quality treatments [28, 29].

According to the 2010 annual report from the Korean nationwide registry program, the incidence and prevalence of patients undergoing renal replacement therapy were 181.5 and 1,144.4 per million population, respectively [30]. The annual increase in the prevalence has been approximately $12 \%$ during the past decade in Korea [31]. The socioeconomic burden of CKD is alarming in Korea, and total direct and indirect costs associated with CKD were estimated at over 5,000 billion KRWs (5 billion \$) in 2011 [30]. The prevalence of CKD has increased significantly over the past decade, which has resulted in greater use of related health care services [30].

Interestingly, most inequality studies on survival after CKD treatment have been performed in Western society [32-35], despite the high burden of this disease and its contribution to mortality in South Korea. It is not known whether a social gradient in health outcomes exists in South Korea. The implementation of universal health care systems in South Korea has resulted in a collapse of the barrier of health care use, improved access to medical care, high quality care, and low mortality [36, 37]; however, debates on disparities between different SES groups in health outcomes continue [38-40]. Therefore, the present study examined the association between income levels and mortality rates in patients with CKD using data from the Korean National Health Insurance claims database (KNHICD). Our rationale for investigating survival in patients with CKD was to identify socioeconomic inequity that could be addressed through targeted policies and priority health services for patients with low incomes.

\section{Subjects and Methods}

\subsection{Data and Participants}

This study used data from the KNHICD, which includes the information of approximately 1 million patients. The stratified random sample data included age, sex, region, health insurance type, income $10^{\text {th }}$ quintiles, and individual total medical costs based on 2002, and follow-up to 2010 . The National Health Security System is a mandatory social insurance program in Korea, and all citizens are obliged to join this system. The system involves the National Health Insurance (NHI) and Medical Aid programs and is overseen by the Ministry of Health and Welfare. Under this system, all the medical care expenses under the NHI or Medical Aid programs are reimbursed, and these data are stored and managed in the KNHICD. Therefore, the KNHICD contains all the information on reimbursement under the fee-for-service system (NHI) or per diem system (Medical Aid). This cohort data included information such as the unique de-identified number for each patient, age, sex, type of insurance, list of diagnoses according to the International Classification of Diseases (ICD-10), medical costs claimed, prescribed drugs including Peritoneal dialysis (PD) solutions, and surgical history, such as Hemodialysis (HD) or PD catheter insertion, or Kidney transplantation (KT). In addition, the unique de-identified number was linked to information on mortality obtained from the Korean National Statistical Office (NSO).

We conducted a cohort study of newly diagnosed CKD (N18) to investigate the association between income levels and mortality rates. We included a $2.5 \%$ stratified random sample $(\mathrm{n}=$ 1,025,340) of KNHICD enrollees on December 31, 2002. From the pool, we selected 3,994 patients whose primary diagnosis was CKD (N18) between 2002 and 2009. Of these, 822 patients with CKD diagnosed in 2002 were removed as this was considered a wash-out period. After eliminating patients who had submitted claims for CKD in 2002, we selected 3,172 who were free of CKD at the end of 2002.

\subsection{Measures}




\subsection{Follow-up and end points}

The outcome variable for this study was all-cause mortality. The duration of mortality followup was 8 years from January 2003 through December 2010. Patients were observed for at least 12 months from the date of the diagnosis of CKD through June 30, 2010, or until death. We considered the time of kidney transplantation to be censored. The unique de-identified number was linked to information on mortality obtained from the Korean NSO. By law, all deaths of Koreans must be reported to the NSO within a month of occurrence. Death certification by a physician is crucial to improve the accuracy of reporting [41].

\subsection{Socioeconomic status}

Individual income can be estimated from the NHI premium. The health insurance premium is proportion to monthly income, including earnings and property income. The patients with CKD were classified into the following three groups according to income: (1) low income group (Medical aid and below $30 \%$ of the income rank), (2) middle income group (30-70\% of the income rank), and (3) high income group (above $70 \%$ of the income rank).

\subsection{Covariates}

Demographic and classical CKD risk factors were included in this study. Demographic factors included sex, age (-39, 40-49, 50-59, 60-69 and $\geq 70$ years), type of insurance (health insurance or medical aid), and region (urban or rural). The comorbidities of the patients were identified by reviewing their medical history during the last 1 year before the diagnosis of CKD. Diagnoses for hypertension, diabetes mellitus, cerebrovascular accident, congestive heart failure, ischemic heart disease, anemia, cancer, and glomerulonephritis were identified on the basis of previous literature $[42,43]$.

\subsection{Statistical analysis}

Distribution of the general characteristics of the patients with CKD at baseline was determined. Kaplan-Meier survival curves were calculated, and the log-rank test was used for comparisons of unadjusted survival rates. First, we investigate the association between SES and mortality among all the patients with CKD. Second, we compared patients with CKD who initiated dialysis at baseline and those who did not initiate dialysis. To delineate the predictors of mortality, Cox proportional hazard analysis was performed. The level of significance was set at $\mathrm{P}<0.05$. SAS 9.3 (SAS Institute, Cary, NC) was used for the analysis.

\section{Results}

Table 1 presents the socio-demographic characteristics of the study participants at baseline. Of the 3,172 participants, 991 (31.2\%), 967 (30.5\%), and 1,214 (38.3\%) were included in the low, middle, and high income groups, respectively.

Figure 1 presents the Kaplan-Meier survival curves according to the income groups. There were no differences in survival rates according to the income levels of the patients with CKD (log rank $\mathrm{P}<0.244$ ). Table 2 presents the results of the Cox proportional hazards analysis, which assessed the association between income levels and mortality rates. After adjusting for covariates including risk factors, we found that the low income group was significantly associated with a high mortality rate (HR 1.298 [1.082-1.556]). CKD patients with diabetes mellitus, cerebrovascular disease, congestive heart failure, ischemic heart failure, ischemic heart disease, and cancer had a higher mortality rate compare to that for those without these disease 1 year before the diagnosis of CKD.

Table 3 presents the results of the subgroup analysis for mortality according to the initiation of dialysis (both peritoneal dialysis and hemodialysis) within 1 year after the diagnosis of CKD. 
Patients in the low income group who initiated dialysis had a high mortality rate. However, when considering patients who did not initiate dialysis, there was no significant difference in mortality rates between the income groups (HR 1.528 [1.122-2.082]).

\section{Discussion}

This population-based study examined the association between income levels and mortality rates in patients with CKD using data from the KNHICD. After adjusting for comorbidities, CKD patients with low incomes and patients with low incomes initiating dialysis had significantly high all-cause mortality rates. Our findings are consistent with the results of other studies investigating the relationship between SES and post-CKD survival in other populations [21-26]. Mortality was substantially higher in the low SES group than in the high SES group in Western countries, including US, UK, and European countries [10, 19, 22, 35, 44], and similar results have been obtained in Asian countries, including Korea [24, 42]. The type of health insurance (i.e., medical aid) and comorbidities in Korean patients undergoing dialysis were associated with independent predictors of mortality [43, 45].

Studies from other countries have demonstrated that CKD patients of low SES may have high all-cause mortality rates, after controlling for risk factors of CKD such as diabetes mellitus, hypertension, cerebrovascular accident, and congestive heart failure [19, 21-26, 35, 42]. However, in South Korea, a more comprehensive analysis is needed, and national representative studies on this topic are limited, although the burden of CKD in Korea has gradually increased. The present study may be of particular importance in South Korea where debates on the inequality in health outcomes continue despite universal health coverage [40]. The NHI program in Korea aimed to eliminate primary health inequality, and may play an important role in closing the medical accessibility gap between patients based on SES. Co-payment amounts are notably low and homogeneously priced, making cost less of a barrier for receiving proper medical care.

During the last few decades, studies have suggested that there are multiple reasons for socioeconomic inequality in health or mortality $[6,46]$ : poor health behaviors, material deprivation, psychosocial attributes, early life exposure, biological risk factors, and late recognition of the disease. Several plausible mechanisms may explain why CKD patients of low SES have high allcause mortality rates. A Korean study suggested that individuals of low SES have high morbidity rates, low health status, and negative behaviors such as smoking, drinking alcohol, and irregular exercise [38]. These findings indicate that individuals of low SES are susceptible to having high CKD mortality rates. In addition, low awareness of CKD may contribute to the high mortality rates in individuals of low SES. The awareness of early and advanced CKD is low even in industrialized nations, and has been reported to be $<20 \%$ [47]. Some studies have suggested that low awareness of CKD or low health literacy is associated with high mortality and all-cause mortality rates attributable to CKD in individuals of low SES [22, 26].

To address the problem of mortality inequality, early recognition of CKD needs to be promoted. The World Kidney Day campaign had a positive impact on increasing awareness and managing risk factors for CKD [48]. Moreover, adequate prevention strategies or treatments need to be provided to low income groups. Given that congestive heart failure, coronary artery disease, diabetes, and anemia were prevalent in patients who died [42], efforts for appropriate management of CKD and its risk factors should be focused on reducing mortality in individuals of low SES. Based on the results of Korea National Health and Nutrition Examination Survey, since increased diabetes and improved diabetic control neutralized their impact on CKD, improved blood pressure was the fundamental reason for the decrease [49]. Such study implicated that various health-related behaviors may have indirectly affected the decrease of CKD through the effect in controlling blood pressure and diabetes. Therefore, more screening and prevention programs for CKD are needed for individuals of low SES. Setting up prevention and early detection programs for individuals of low SES will help reduce the inequality in mortality. Moreover, governments should encourage 
individuals of low SES to participate actively in these programs. Furthermore, to relieve the financial burden on patients with CKD, additional benefits can be introduced.

The strengths of this study are its population-based design and data collection from the KNHICD, which is nationally representative. Additionally, using the unique personal identity number of each Korean resident and linking it to the national mortality data, follow-up was completed. Despite these strengths, the study has some limitations. First, potential confounding factors for mortality were unavailable, such as data regarding residual renal function, biomarkers of inflammation or nutrition, and doses of dialysis. Second, the database used does not include information on tobacco use, dietary habits, or other behavioral factors, and these may be risk factors and prognostic factors for patients with CKD. Third, this study used individual income estimated from the health insurance premium instead of real income.

\section{Conclusion}

The relationship between SES and mortality rates in patients with CKD is well established across the world. The findings indicate that CKD patients with low incomes have high mortality rates in Korea. Promotion of targeted policies and priority health services for patients with low incomes may help reduce the mortality rate in this vulnerable group.

\section{References}

1. El Nahas AM, Bello AK. Chronic kidney disease: the global challenge The Lancet. 2005; 365: $331-340$

2. Couser WG, Remuzzi G, Mendis S, Tonelli M. The contribution of chronic kidney disease to the global burden of major noncommunicable diseases Kidney international. 2011; 80: 1258-1270

3. Imai E, Matsuo S. Chronic kidney disease in Asia The Lancet. 2008; 371: 2147-2148

4. Lozano R, Naghavi M, Foreman $\mathrm{K}$ et al. Global and regional mortality from 235 causes of death for 20 age groups in 1990 and 2010: a systematic analysis for the Global Burden of Disease Study 2010 The Lancet. 2013; 380: 2095-2128

5. Martins D, Agodoa L, Norris K. Chronic kidney disease in disadvantaged populations International journal of nephrology. 2012; 2012

6. Adler NE, Ostrove JM. Socioeconomic status and health: what we know and what we don't Annals of the New York academy of Sciences. 1999; 896: 3-15

7. Young EW, Mauger EA, Jiang K-H, Port FK, Wolfe RA. Socioeconomic status and endstage renal disease in the United States Kidney international. 1994; 45: 907-911

8. Fored CM, Ejerblad E, Fryzek JP et al. Socio-economic status and chronic renal failure: a population-based case-control study in Sweden Nephrology Dialysis Transplantation. 2003; 18: $82-88$

9. Lipworth L, Mumma MT, Cavanaugh $\mathrm{KL}$ et al. Incidence and predictors of end stage renal disease among low-income blacks and whites PloS one. 2012; 7: e48407

10. Neovius $\mathrm{M}$, Jacobson SH, Eriksson JK, Elinder C-G, Hylander B. Mortality in chronic kidney disease and renal replacement therapy: a population-based cohort study BMJ open. 2014; 4: e004251 
11. Maheswaran R, Payne N, Meechan D et al. Socioeconomic deprivation, travel distance, and renal replacement therapy in the Trent Region, United Kingdom 2000: an ecological study Journal of epidemiology and community health. 2003; 57: 523-524

12. Hsu C-y, Lin F, Vittinghoff E, Shlipak MG. Racial differences in the progression from chronic renal insufficiency to end-stage renal disease in the United States Journal of the American Society of Nephrology. 2003; 14: 2902-2907

13. Hall YN, Choi Al, Himmelfarb J, Chertow GM, Bindman AB. Homelessness and CKD: a cohort study Clinical Journal of the American Society of Nephrology. 2012: CJN. 00060112

14. Kausz AT, Obrador GT, Arora P, Ruthazer R, Levey AS, Pereira BJ. Late initiation of dialysis among women and ethnic minorities in the United States Journal of the American Society of Nephrology. 2000; 11: 2351-2357

15. Perneger TV, Whelton PK, Klag MJ. Race and end-stage renal disease: socioeconomic status and access to health care as mediating factors Archives of internal medicine. 1995; 155: $1201-1208$

16. Bello AK, Peters J, Rigby J, Rahman AA, El Nahas M. Socioeconomic status and chronic kidney disease at presentation to a renal service in the United Kingdom Clinical Journal of the American Society of Nephrology. 2008; 3: 1316-1323

17. Merkin SS, Coresh J, Roux AVD, Taylor HA, Powe NR. Area socioeconomic status and progressive CKD: the Atherosclerosis Risk in Communities (ARIC) Study American Journal of Kidney Diseases. 2005; 46: 203-213

18. Alves TP, Wang X, Wright JT et al. Rate of ESRD exceeds mortality among African Americans with hypertensive nephrosclerosis Journal of the American Society of Nephrology. 2010; 21: 1361-1369

19. Hossain M, Palmer D, Goyder E, El Nahas A. Association of deprivation with worse outcomes in chronic kidney disease: findings from a hospital-based cohort in the United Kingdom Nephron. Clinical Practice. 2011; 120: c59-70

20. Norris K, Bourgoigne J, Gassman J et al. Cardiovascular outcomes in the African American Study of kidney disease and hypertension (AASK) Trial American journal of kidney diseases. 2006; 48: 739-751

21. $\mathrm{Xu} \mathrm{R}$, Han Q-F, Zhu T-Y et al. Impact of individual and environmental socioeconomic status on peritoneal dialysis outcomes: a retrospective multicenter cohort study PloS one. 2012; 7: e50766

22. Cavanaugh $\mathrm{KL}$, Wingard $\mathrm{RL}$, Hakim RM et al. Low health literacy associates with increased mortality in ESRD Journal of the American Society of Nephrology. 2010; 21: 1979-1985

23. de Andrade Bastos K, Qureshi AR, Lopes AA et al. Family income and survival in Brazilian Peritoneal Dialysis Multicenter Study Patients (BRAZPD): time to revisit a myth? Clinical Journal of the American Society of Nephrology. 2011; 6: 1676-1683 
24. Han SH, Ahn SV, Yun JY, Tranaeus A, Han D-S. Effects of icodextrin on patient survival and technique success in patients undergoing peritoneal dialysis Nephrology Dialysis Transplantation. 2011: gfr580

25. MacRae JM, Rose CL, Jaber BL, Gill JS. Utilization and outcome of 'out-of-center hemodialysis' in the United States: a contemporary analysis Nephron. Clinical practice. 2010; 116: c53

26. Wen $\mathrm{CP}$, Cheng TYD, Tsai MK et al. All-cause mortality attributable to chronic kidney disease: a prospective cohort study based on 462293 adults in Taiwan The Lancet. 2008; 371: 2173-2182

27. Sesso R, Rodrigues-Neto JF, Ferraz MB. Impact of socioeconomic status on the quality of life of ESRD patients American Journal of Kidney Diseases. 2003; 41: 186-195

28. Ashby V, Kalbfleisch J, Wolfe R, Lin M, Port F, Leichtman A. Geographic variability in access to primary kidney transplantation in the United States, 1996-2005 American journal of transplantation. 2007; 7: 1412-1423

29. Weng $\mathrm{FL}$, Joffe $\mathrm{MM}$, Feldman HI, Mange KC. Rates of completion of the medical evaluation for renal transplantation American journal of kidney diseases. 2005; 46: 734 745

30. Jin DC, Ha IS, Kim NH et al. Brief report: renal replacement therapy in Korea, 2010 Kidney Research and Clinical Practice. 2012; 31: 62-71

31. Jin DC. Current status of dialysis therapy in Korea The Korean journal of internal medicine. 2011; 26: 123-131

32. Merkin SS, Roux AVD, Coresh J, Fried LF, Jackson SA, Powe NR. Individual and neighborhood socioeconomic status and progressive chronic kidney disease in an elderly population: The Cardiovascular Health Study Social science \& medicine. 2007; 65: 809-821

33. Mehrotra R, Kermah DA, Salusky IB et al. Chronic kidney disease, hypovitaminosis D, and mortality in the United States Kidney international. 2009; 76: 977-983

34. Weiner DE, Tighiouart $H, A$ min $M G$ et al. Chronic kidney disease as a risk factor for cardiovascular disease and all-cause mortality: a pooled analysis of community-based studies Journal of the American Society of Nephrology. 2004; 15: 1307-1315

35. Goldfarb-Rumyantzev AS, Rout P, Sandhu GS, Khattak M, Tang H, Barenbaum A. Association between social adaptability index and survival of patients with chronic kidney disease Nephrology Dialysis Transplantation. 2010; 25: 3672-3681

36. Jeong H-S. Korea's National Health Insurance-lessons from the past three decades Health Affairs. 2011; 30: 136-144

37. Kwon S. Thirty years of national health insurance in South Korea: lessons for achieving universal health care coverage Health policy and planning. 2009; 24: 63-71

38. Kim H-J, Ruger JP. Socioeconomic disparities in behavioral risk factors and health outcomes by gender in the Republic of Korea BMC Public Health. 2010; 10: 195 
39. Khang $\mathrm{Y}-\mathrm{H}$, Lynch J, Yun S, Lee S. Trends in socioeconomic health inequalities in Korea: use of mortality and morbidity measures Journal of Epidemiology and Community Health. 2004; 58: 308-314

40. Khang Y-H, Lynch JW, Kaplan GA. Health inequalities in Korea: age-and sex-specific educational differences in the 10 leading causes of death International Journal of Epidemiology. 2004; 33: 299-308

41. Lee DH, Shin HR, Ahn DH, Chun BY, Kam S, Ahn YO. Accuraey of Cancer Death Certificates in KOREA: A comparison between diagnoses in the central cancer registry and certified underlying causes of death Journal of the Korean Cancer Association. 2000; 32: $210-219$

42. Keith DS, Nichols GA, Gullion CM, Brown JB, Smith DH. Longitudinal follow-up and outcomes among a population with chronic kidney disease in a large managed care organization Archives of internal medicine. 2004; 164: 659-663

43. Kim $\mathrm{H}, \mathrm{Kim} \mathrm{KH}$, Park $\mathrm{K}$ et al. A population-based approach indicates an overall higher patient mortality with peritoneal dialysis compared to hemodialysis in Korea Kidney international. 2014; 86: 991-1000

44. Roderick PJ, Atkins RJ, Smeeth L et al. CKD and mortality risk in older people: a community-based population study in the United Kingdom American journal of kidney diseases. 2009; 53: 950-960

45. Lee $\mathrm{S}, \mathrm{Ryu}$ J-H, Kim $\mathrm{H}$ et al. An Assessment of Survival among Korean Elderly Patients Initiating Dialysis: A National Population-Based Study PloS one. 2014; 9: e86776

46. Khang $\mathrm{Y}-\mathrm{H}$, Kim HR. Explaining socioeconomic inequality in mortality among South Koreans: an examination of multiple pathways in a nationally representative longitudinal study International journal of epidemiology. 2005; 34: 630-637

47. Vassalotti JA, Li S, McCullough PA, Bakris GL. Kidney early evaluation program: a community-based screening approach to address disparities in chronic kidney disease. Seminars in nephrology. Elsevier: 2010; 66-73

48. Chin HJ, Ahn JM, Na KY et al. The effect of the World Kidney Day campaign on the awareness of chronic kidney disease and the status of risk factors for cardiovascular disease and renal progression Nephrology Dialysis Transplantation. 2010; 25: 413-419

49. Lee SW, Kim YC, Oh S-W et al. Trends in the prevalence of chronic kidney disease, other chronic diseases and health-related behaviors in an adult Korean population: data from the Korea National Health and Nutrition Examination Survey (KNHANES) Nephrology Dialysis Transplantation. 2011: gfr154 
Table 1. Socio-demographic characteristics of the study participants at baseline.

\begin{tabular}{|c|c|c|}
\hline Total & 3,172 & \\
\hline \multicolumn{3}{|l|}{ Income } \\
\hline Low & 991 & 31.2 \\
\hline Middle & 967 & 30.5 \\
\hline High & 1,214 & 38.3 \\
\hline \multicolumn{3}{|l|}{ Sex } \\
\hline Male & 1,823 & 57.5 \\
\hline Female & 1,349 & 42.5 \\
\hline \multicolumn{3}{|l|}{ Age } \\
\hline$<39$ & 383 & 12.1 \\
\hline $40-49$ & 428 & 13.5 \\
\hline $50-59$ & 612 & 19.3 \\
\hline $60-69$ & 790 & 24.9 \\
\hline$>70$ & 959 & 30.2 \\
\hline \multicolumn{3}{|l|}{ Type of insurance } \\
\hline Health insurance & 2,812 & 88.7 \\
\hline Medical aid & 360 & 11.4 \\
\hline \multicolumn{3}{|l|}{ City } \\
\hline Rural & 1,010 & 31.8 \\
\hline Urban & 2,162 & 68.2 \\
\hline \multicolumn{3}{|l|}{ Hypertension } \\
\hline No & 915 & 28.9 \\
\hline Yes & 2,257 & 71.2 \\
\hline \multicolumn{3}{|l|}{ Diabetes mellitus } \\
\hline No & 1,824 & 57.5 \\
\hline Yes & 1,348 & 42.5 \\
\hline \multicolumn{3}{|c|}{ Cerebrovascular accident } \\
\hline No & 2,846 & 89.7 \\
\hline Yes & 326 & 10.3 \\
\hline \multicolumn{3}{|c|}{ Congestive heart failure } \\
\hline No & 3,000 & 94.6 \\
\hline Yes & 172 & 5.4 \\
\hline \multicolumn{3}{|c|}{ Ischemic heart disease } \\
\hline No & 2,589 & 81.6 \\
\hline Yes & 583 & 18.4 \\
\hline \multicolumn{3}{|l|}{ Anemia } \\
\hline No & 2,674 & 84.3 \\
\hline Yes & 498 & 15.7 \\
\hline \multicolumn{3}{|l|}{ Cancer } \\
\hline No & 2,838 & 89.5 \\
\hline Yes & 334 & 10.5 \\
\hline \multicolumn{3}{|l|}{ Glomerulonephritis } \\
\hline No & 2,840 & 89.5 \\
\hline Yes & 332 & 10.5 \\
\hline \multicolumn{3}{|c|}{ Dialysis (hemodialysis or peritoneal dialysis) } \\
\hline No & 2,414 & 76.1 \\
\hline Yes & 758 & 23.9 \\
\hline \multicolumn{3}{|c|}{ Status during the study period } \\
\hline alive & 2,329 & 73.4 \\
\hline died & 843 & 26.6 \\
\hline
\end{tabular}


Table 2. Adjusted hazard ratios for mortality.

Mortality

$\begin{array}{llll}\text { Variable } & \text { HR } & 95 \% \mathrm{CI} & \text { P-value }\end{array}$

\begin{tabular}{|c|c|c|c|c|}
\hline \multicolumn{5}{|l|}{ Income } \\
\hline Low & 1.298 & 1.082 & 1.556 & 0.005 \\
\hline Middle & 1.104 & 0.935 & 1.304 & 0.244 \\
\hline High & 1.000 & & & \\
\hline \multicolumn{5}{|l|}{ Sex } \\
\hline Male & 1.241 & 1.076 & 1.430 & 0.003 \\
\hline Female & 1.000 & & & \\
\hline \multicolumn{5}{|l|}{ Age } \\
\hline$<39$ & 1.000 & & & \\
\hline $40-49$ & 1.558 & 0.954 & 2.544 & 0.076 \\
\hline $50-59$ & 2.396 & 1.542 & 3.723 & 0.000 \\
\hline $60-69$ & 4.243 & 2.780 & 6.476 & $<0.0001$ \\
\hline$>70$ & 10.208 & 6.733 & 15.478 & $<0.0001$ \\
\hline \multicolumn{5}{|l|}{ Type of insurance } \\
\hline Health insurance & 1.000 & & & \\
\hline Medical aid & 1.148 & 0.858 & 1.537 & 0.354 \\
\hline \multicolumn{5}{|l|}{ City } \\
\hline Rural & 1.081 & 0.938 & 1.247 & 0.281 \\
\hline Urban & 1.000 & & & \\
\hline \multicolumn{5}{|l|}{ Hypertension } \\
\hline No & 1.000 & & & \\
\hline Yes & 0.988 & 0.832 & 1.174 & 0.892 \\
\hline \multicolumn{5}{|l|}{ Diabetes mellitus } \\
\hline No & 1.000 & & & \\
\hline Yes & 1.494 & 1.296 & 1.721 & $<0.0001$ \\
\hline \multicolumn{5}{|c|}{ Cerebrovascular disease } \\
\hline No & 1.000 & & & \\
\hline Yes & 1.377 & 1.140 & 1.663 & 0.001 \\
\hline \multicolumn{5}{|c|}{ Congestive heart failure } \\
\hline No & 1.000 & & & \\
\hline Yes & 1.449 & 1.149 & 1.827 & 0.002 \\
\hline \multicolumn{5}{|c|}{ Ischemic heart disease } \\
\hline No & 1.000 & & & \\
\hline Yes & 1.183 & 1.007 & 1.391 & 0.041 \\
\hline \multicolumn{5}{|l|}{ Anemia } \\
\hline No & 1.000 & & & \\
\hline Yes & 0.951 & 0.790 & 1.144 & 0.592 \\
\hline \multicolumn{5}{|l|}{ Cancer } \\
\hline No & 1.000 & & & \\
\hline Yes & 1.299 & 1.065 & 1.583 & 0.010 \\
\hline \multicolumn{5}{|l|}{ Glomerulonephritis } \\
\hline No & 1.000 & & & \\
\hline Yes & 0.798 & 0.616 & 1.032 & 0.085 \\
\hline \multicolumn{5}{|c|}{ Dialysis (hemodialysis or peritoneal dialysis) } \\
\hline No & 1.000 & & & \\
\hline Yes & 2.259 & 1.951 & 2.615 & $<0.0001$ \\
\hline
\end{tabular}


Table 3. Adjusted hazard ratio for mortality according to initiation of dialysis at baseline.

Patients with dialysis

Variable

HR
$95 \% \mathrm{CI}$

P-value

HR
Patients without dialysis

\begin{tabular}{|c|c|c|c|c|c|c|c|}
\hline 1.528 & 1.122 & 2.082 & 0.007 & 1.166 & 0.928 & 1.465 & 0.187 \\
\hline 1.040 & 0.781 & 1.385 & 0.788 & 1.117 & 0.908 & 1.374 & 0.294 \\
\hline 1.000 & & & & 1.000 & & & \\
\hline 1.144 & 0.901 & 1.452 & 0.271 & 1.291 & 1.079 & 1.543 & 0.005 \\
\hline 1.000 & & & & 1.000 & & & \\
\hline 1.000 & & & & 1.000 & & & \\
\hline 1.168 & 0.568 & 2.399 & 0.673 & 1.863 & 0.942 & 3.684 & 0.074 \\
\hline 2.486 & 1.342 & 4.606 & 0.004 & 2.129 & 1.119 & 4.049 & 0.021 \\
\hline 3.502 & 1.910 & 6.421 & $<0.0001$ & 4.741 & 2.595 & 8.662 & $<0.0001$ \\
\hline 7.273 & 3.957 & 13.365 & $<0.0001$ & 12.053 & 6.686 & 21.727 & $<0.0001$ \\
\hline 1.000 & & & & 1.000 & & & \\
\hline 0.764 & 0.464 & 1.257 & 0.289 & 1.448 & 1.003 & 2.090 & 0.048 \\
\hline 1.001 & 0.784 & 1.278 & 0.993 & 1.135 & 0.951 & 1.355 & 0.160 \\
\hline 1.000 & & & & 1.000 & & & \\
\hline 1.000 & & & & 1.000 & & & \\
\hline 0.934 & 0.704 & 1.239 & 0.636 & 1.060 & 0.850 & 1.324 & 0.604 \\
\hline 1.000 & & & & 1.000 & & & \\
\hline 1.463 & 1.141 & 1.876 & 0.003 & 1.477 & 1.239 & 1.760 & $<0.0001$ \\
\hline 1.000 & & & & 1.000 & & & \\
\hline 1.633 & 1.176 & 2.267 & 0.003 & 1.273 & 1.008 & 1.607 & 0.043 \\
\hline 1.000 & & & & 1.000 & & & \\
\hline 1.280 & 0.853 & 1.920 & 0.232 & 1.512 & 1.135 & 2.013 & 0.005 \\
\hline 1.000 & & & & 1.000 & & & \\
\hline 1.219 & 0.911 & 1.631 & 0.184 & 1.175 & 0.965 & 1.431 & 0.108 \\
\hline 1.000 & & & & 1.000 & & & \\
\hline 0.873 & 0.661 & 1.153 & 0.338 & 1.019 & 0.793 & 1.308 & 0.885 \\
\hline 1.000 & & & & 1.000 & & & \\
\hline 0.612 & 0.381 & 0.984 & 0.043 & 0.920 & 0.675 & 1.253 & 0.596 \\
\hline 1.000 & & & & 1.000 & & & \\
\hline 1.597 & 1.122 & 2.273 & 0.009 & 1.214 & 0.952 & 1.549 & 0.118 \\
\hline
\end{tabular}


Figure 1. Kaplan-Meier survival curves according to the income groups.

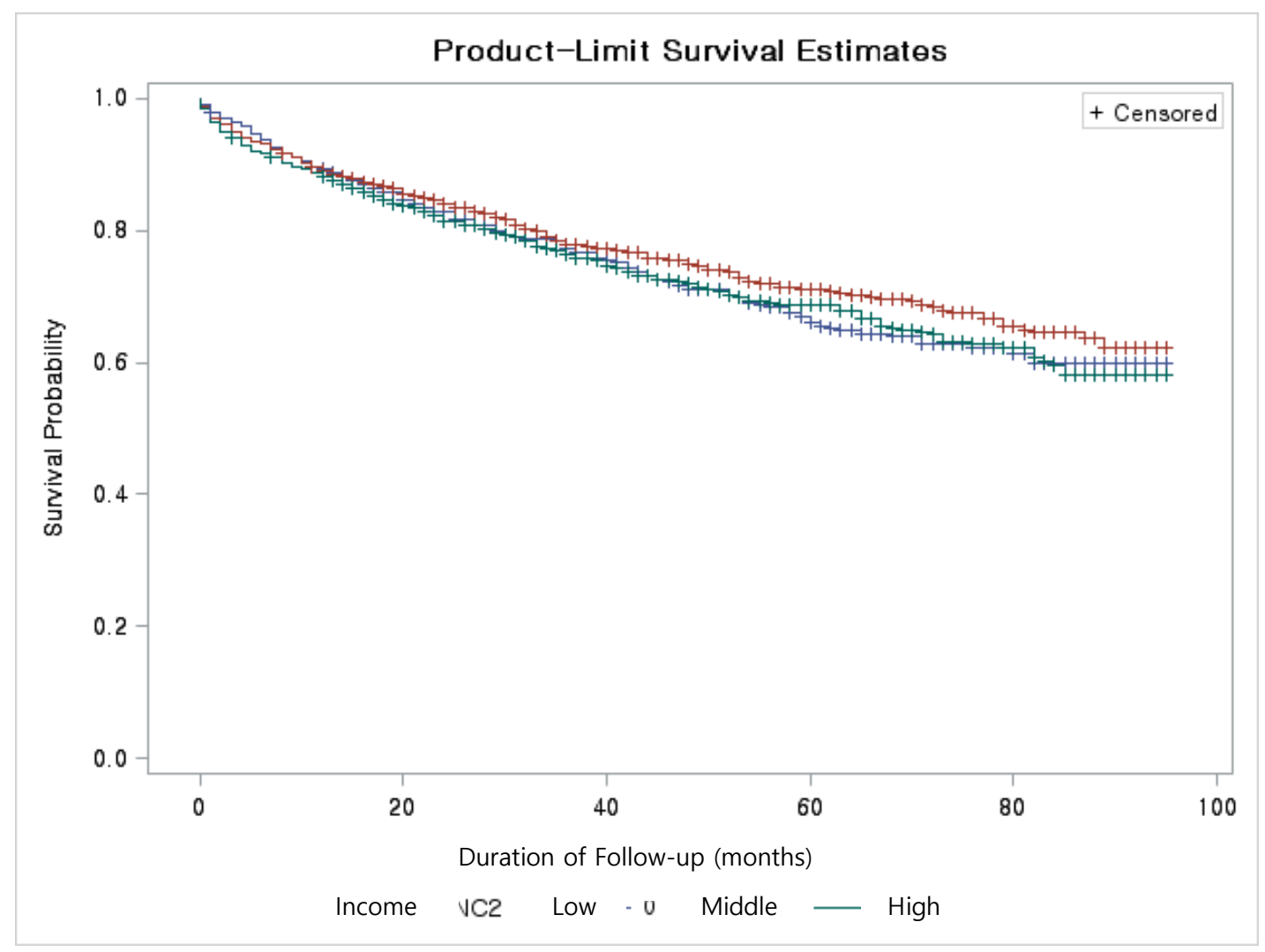

